\title{
36 Recommended fluid intake
}

The average human body is made up of around $60 \%$ water. Through the skin, but also the kidneys, intestines and respirated air, it loses 1.5-2.5 liters of water daily and much more during activities in hot environments or from fever or diarrhea. The losses are compensated for by ingestion of water from solid food (500-700 ml per day) or metabolism (200-300 ml per day) and from drinking fluids. Under everyday conditions, the recommended drinking amount is approximately $20 \mathrm{ml}$ per kg of body weight, and $15 \mathrm{ml}$ in persons older than 65 years. This includes diuretic fluids like coffee or tea. Although caffeine contained in these drinks inhibits the sodium and water absorption in the renal tubules, regular enjoyment of caffeine is associated with a rapid habituation process and coffee or tea then affect the fluids balance according to the ingested amount of water consumed.

Even though the feeling of thirst is occasionally unreliable (particularly in older people), the common recommendation to drink copious amounts of fluids daily is questionable. Positive effects on appetite, weight, skin, renal function or on other organs have not been scientifically substantiated to date.

What is undisputed, however, is the fact that dehydration should be avoided. Even moderate water losses can cause sluggishness, fatigue and possibly even headaches as well. Fluid deficits starting at $2 \%$ (approximately $1000 \mathrm{ml}$ ) can seriously impair physical and mental performance. Fluids intake of less than $800 \mathrm{ml}$ per day have been associated with a limited concentration potential of the kidneys.

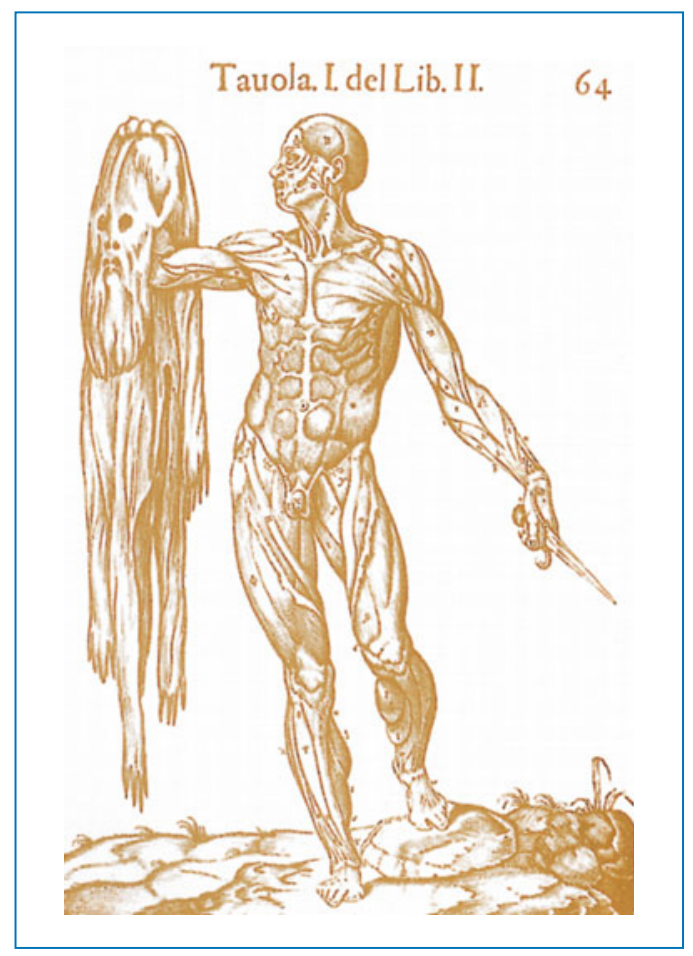

- Fig. 36.1 Bercerra (1560), Anatomia del corpo humano. (Courtesy of Andreas Verlag, Salzburg)

Urea levels are then elevated and substantially cloud consciousness. The parallel elevations in increasing potassium concentrations trigger tachycardia and cardiac rhythmus disorders. Chronically high losses of bodily water are life-threatening. 